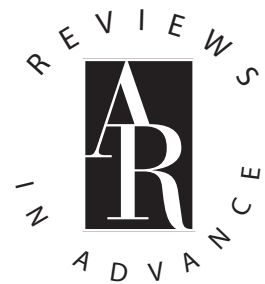

\title{
Climate Relicts: Past, Present, Future
}

\section{Arndt Hampe ${ }^{1}$ and Alistair S. Jump ${ }^{2}$}

${ }^{1}$ Department of Integrative Ecology, Estación Biológica de Doñana, 41092 Sevilla, Spain; email: arndt@pierroton.inra.fr

${ }^{2}$ Biological and Environmental Sciences, School of Natural Sciences, University of Stirling, Stirling, FK9 4LA, United Kingdom; email: a.s.jump@stir.ac.uk

Annu. Rev. Ecol. Evol. Syst. 2011. 42:313-33

The Annual Review of Ecology, Evolution, and Systematics is online at ecolsys.annualreviews.org

This article's doi:

10.1146/annurev-ecolsys-102710-145015

Copyright (C) 2011 by Annual Reviews. All rights reserved

$1543-592 X / 11 / 1201-0313 \$ 20.00$

\section{Keywords}

biotic interactions, climate change, climatic stress, population viability, refugium, retreating range margin

\section{Abstract}

Populations left behind during climate-driven range shifts can persist in enclaves of benign environmental conditions within an inhospitable regional climate. Such climate relicts exist in numerous plant and animal species worldwide, yet our knowledge of them is fragmented and lacks a general framework. Here we synthesize the empirical evidence considering $(a)$ relict habitats, $(b)$ abiotic and biotic constraints on population dynamics, $(c)$ mechanisms promoting population persistence, and $(d)$ uncertainties concerning their future prospects. We identify three major types of climate relicts: (a) those primarily constrained by climate-driven abiotic factors, $(b)$ those restricted to areas that are inaccessible to antagonistic species for climatic reasons, and $(c)$ those requiring a host or mutualistic species that is itself limited by climate. Understanding the formation and functioning of climate relicts is essential for their conservation and for our understanding of the response of species and populations to climate change. 
Last Glacial

Maximum (LGM): maximum extent of ice sheets during the last glacial period, culminating approximately $21 \mathrm{ka}$ before present

\section{INTRODUCTION}

The potential impacts of current climate change on the distribution and conservation of biodiversity are the subject of global concern. One major consequence of rising temperatures is that many plant and animal species worldwide are moving toward higher elevations and latitudes in response to shifts in the environmental conditions to which they are adapted (Parmesan 2006). Accordingly, many model-based projections of future species ranges have predicted generalized and significant distribution shifts during the coming decades (Thuiller et al. 2008, Pereira et al. 2010). Changes in geographic distributions do not simply result from the simultaneous migration of populations throughout the range. Instead, they are generated by widespread establishment of new populations at the leading edge of a species distribution and extinction of populations at the retreating edge (Hampe \& Petit 2005, Thuiller et al. 2008). Hence, even those species whose distribution range does not shrink in response to climate change suffer increased rates of population turnover and extinction.

Climatic changes and species range shifts have been a recurrent phenomenon throughout the history of Earth. At the retreating range limit, retractions are often not complete but instead leave behind some populations that remain as relicts, isolated in enclaves of benign environmental conditions within an inhospitable regional climate. The awareness of the existence of such climate relicts is not new. For instance, Noack (1922) listed 90 plant species widespread at high latitudes of the Northern Hemisphere that have some outposts in the Alps. Cain (1930) reported that out of 248 woody plant species recorded in the Great Smoky Mountains (southern Appalachians) no less than $63(26 \%)$ reach their southern range limit in this region. Of a further 56 species (23\%) that are endemic to the region and its surroundings, many possess northern sister species. Similarly, numerous mammal species of mostly boreal distribution stretch out into mountain ranges of the southwestern United States (Brown 1971). More recently, Nekola (1999) reported that the surroundings of ice-filled caves in northeast Iowa in the American Midwest harbor more than 60 vascular plants, numerous land snails, and mites of boreal distribution. Gorchakovskii \& Zolotareva (2006) identified relict stands of 66 plant species in three species-rich mountainsteppe ecosystems situated in the southern Urals, and Danin (1999) reported that hundreds of Mediterranean species can be found in the shelter of rock outcrops located in the deserts of the Near East.

Recent research is revealing that the phenomenon is even more widespread than previously realized. In fact, many terrestrial species found at temperate and higher latitudes still have some relict populations in the regions they inhabited during the cold stages of the Quaternary. These populations reside near the current low-latitudinal margins of the range, and their great antiquity renders them disproportionately important for the conservation of the genetic diversity, phylogenetic history, and evolutionary potential of species (Hampe \& Petit 2005). In addition, many further relict populations have been left behind "on the way" during range shifts of species after the Last Glacial Maximum (LGM). Although such populations are younger and less evolutionarily unique, they contribute significantly to biodiversity, can exert important functions within local plant communities and ecosystems (Eriksson 2000), serve as models for understanding species' dynamics in past environments (Horsak et al. 2010), and help improve the performance of species distribution models (Thuiller et al. 2008).

Climate relicts are, therefore, highly important components of local and regional biodiversity. Appropriate strategies for their conservation require a sound understanding of their origins, current condition, and future prospects. However, the value of such knowledge stretches beyond conservation concerns to the core of our understanding of how populations and species respond to changes in climate. How do climate relicts manage to persist close to their environmental 
tolerance limits? Which ecological and microevolutionary processes are they experiencing? What are their prospects under continued climatic change? These are highly relevant questions at a moment when global climate is warming rapidly, representing a major threat to Earth's biodiversity. A wealth of new evidence from disciplines such as phylogeography, paleoecology, ecophysiology, population ecology, evolutionary genetics, and global-change biology can revolutionize our understanding of this subject. However, no attempts have been made to date to synthesize this information into a common framework. Consequently, our understanding of climate relicts lags behind the significant conceptual and empirical advances made in related fields during recent years. Here, we attempt to provide a first integrated overview of climate relicts and the intrinsic and extrinsic determinants of their fate.

Our review is structured around four major topics. First, we briefly review the historical and current use of the term climate relict and propose a new, more operative conceptual framework that accounts for the empirical evidence now available. Second, we explore environmental characteristics of the habitats that harbor climate relicts. Third, we describe the empirical evidence for different climatic constraints on population performance and inquire which ecological strategies enhance the persistence of relicts in their particular situation. Finally, we discuss the uncertainties that are related to the future prospects of climate relicts in a rapidly changing environment. Our review emphasizes temperate and higher-latitude terrestrial organisms, which reflect our personal expertise as well as the availability of empirical accounts.

\section{WHAT IS A CLIMATE RELICT?}

\section{Established Notions}

The term climate relict was coined in the early days of biogeography and still features in most textbooks of the field. It has traditionally been applied to species whose geographic distribution has contracted relatively recently in Earth's history owing to changes in climate. The concept stems from a central goal of historical biogeography: to infer past environmental conditions from changes in species distributions. The strongest evidence for the past occupation of any area by a particular species is provided by the fossil record, yet most species hardly appear as fossils. Moreover, among those species that do have a fossil record, data are often too sparse, uneven, or ambiguous to allow detailed biogeographic interpretations and reconstructions. Therefore, the presence of species outside their typical range was, until relatively recently, an important complementary source of information for inferring past climates.

The status of a species as a climate relict has typically been inferred on biogeographic grounds, that is, using its current geographic distribution and its association with specific habitats. Three classes of extant relicts have been considered most commonly (Cox \& Moore 2010): (a) Tertiary relicts receded with the increasingly drier and cooler climatic conditions during the late Tertiary and early Quaternary, (b) glacial relicts were more widely distributed during Quaternary cold stages and have experienced significant range contractions since the LGM, and (c) postglacial relicts persist in regions of the world that experienced warmer periods in the early Holocene than those experienced today.

Although the use of climate relicts in biogeography has historically been instructive and valuable, the approach has now largely been superseded by the discovery of much more powerful physical, chemical, and biological proxies for past climatic conditions such as isotopic variation from ice cores, speleothems, high-resolution fossil records, or marine and lake sediment composition (Wanner et al. 2008, Pound et al. 2011). At the same time, molecular methods have allowed us to infer historical population and range dynamics with previously unknown detail and 
to assess how climate and other factors have influenced present-day distributions (Knowles 2009). Both developments have greatly helped with refining our understanding of past environments and resulting range dynamics. They also have unveiled some conceptual caveats concerning the conventional biogeographic notion of climate relicts.

First, virtually all extant species should have experienced recurrent range contractions and expansions in their history. Hence, whether a taxon is considered a relict depends, to a large extent, on how much it reduced its range compared with some reference period; this is ultimately an arbitrary decision (Rodríguez-Sánchez \& Arroyo 2008). Second, the classification of species as climate relicts implies that climate has been the primary factor responsible for the permanent reduction of their distribution, although this relationship can often not be clearly established. In fact, the concept has commonly been expanded to species whose failure to recover from a past climate-driven range contraction has arguably been influenced by nonclimatic reasons, such as a limited colonization ability, interspecific competition, or long-term human impacts (Crochet et al. 2004, Calleja et al. 2009, Schneeweiss \& Schönswetter 2010, Ursenbacher et al. 2010). Third, biogeographic notions of climate relicts tend to focus primarily on species and higher taxonomic levels, although most species have their distribution limited by climate only in some parts of their range while they may thrive and readily expand in others (Franco et al. 2006, Parmesan 2006). More generally, neglecting the intraspecific level means neglecting the variety of environments different populations have been subjected to and the amount of adaptive genetic and phenotypic variation that they have accumulated during their distinct evolutionary trajectories. On the contrary, considering the population level can reveal important aspects of microevolution and conservation in face of a rapidly changing climate (Davis et al. 2005, Jump \& Peñuelas 2005).

\section{Shifting the Paradigm}

Here we propose a new use of the climate relict concept that involves two major conceptual shifts. First, we suggest moving away from a purely descriptive biogeographic context and shifting toward adopting a stronger ecological and (micro)evolutionary focus. Second, we propose abandoning the emphasis on entire species and instead emphasizing those populations that are persisting close to their climatic tolerance limit. This reorientation of the climate relict provides a framework that allows the formulation and testing of specific hypotheses about the response of natural populations to a changing environment.

Through the rest of this paper, we define climate relicts as those populations of a species that persist in isolated enclaves of suitable climate space surrounded by areas with climatic conditions that do not permit the existence of the species. The current confinement of such populations results from a change in climate once more favorable for growth and reproduction, a change that has led to the extinction of conspecific populations that once inhabited these now climatically inhospitable intervening areas. We emphasize that our expanded definition involves a demonstrable link between current climatic conditions and population performance. Such climatic constraints can be either direct or indirect through their mediation on biotic interactions.

Three possible responses of populations to climate change are usually considered (Davis et al. 2005, Parmesan 2006): migration, adaptation, and extinction. Climate relict populations have very limited opportunities for migration. Moreover, many have probably been exposed to stronger and longer-lasting climate-related selection than their conspecifics from the main distribution range (Jansson \& Dynesius 2002). Nevertheless, they have not gone extinct. This particular combination renders climate relicts as instructive models and natural laboratories for investigating how populations will react (and potentially adapt) to ongoing climatic changes (Davis et al. 2005, Hampe \& Petit 2005). 
Given that current global climate is warmer than throughout most of the Pleistocene and further warming seems unavoidable (IPCC 2007), we primarily refer to "cold" relicts, that is, those populations that persist under relatively cooler and more humid microclimatic conditions within a warmer and drier landscape matrix (e.g., in mires, mountain streams, ravines, gorges, or highelevation screes, and grasslands). Our review considers two major types of relict populations: those that originated from range shifts during the present interglacial period (hereafter called Holocene relicts) and those that have survived at least one complete glacial oscillation approximately in situ (hereafter termed pre-LGM relicts).

The concept of climate relicts is intrinsically linked with that of refugia, those areas where relict populations have been able to persist through periods of elevated environmental stress. The refugium concept has recently been an object of intense debate, and several attempts have been made to adapt its definition and use to recent knowledge (e.g., Bennett \& Provan 2008, Médail \& Diadema 2009, Rull 2009). Most authors have pursued a perspective based on past species dynamics and hardly attempted to identify what actually characterizes a refugium beyond the fact that its environmental conditions have presumably allowed species to persist. A notable exception is the recent review of Dobrowski (2011), who defined refugia on climatic grounds as "physiographic settings that can support once prevalent regional climates that have been lost (or are being lost) due to climate shifts" (p. 1023). Here, we follow a similar bottom-up approach for the biological components of refugia by simply considering a refugium as any place that harbors a climate relict population. Both the climatic and the biological definitions apply to historical as well as present-day refugia and are better integrated into ecological theory than definitions based on past species dynamics.

\section{ENVIRONMENTAL SETTINGS FAVORING THE ENDURANCE OF CLIMATE RELICTS}

There are two possible, nonexclusive environmental scenarios that enable the long-term persistence of populations approximately in situ (Figure 1): (a) Climatic variation can be low, or (b) the existing climatic variation can be buffered in a heterogeneous landscape that contains patchy habitats and steep microclimatic gradients. The relevance of each scenario depends on the spatial and temporal scale of observation, because the magnitude of climatic changes experienced by populations will increase as the period of observation increases. As a consequence, Holocene relicts can often be found in relatively small areas that buffer against limited climatic changes (e.g., mires or algific talus slopes) (Nekola 1999, Spitzer \& Danks 2006), whereas pre-LGM relicts are almost exclusively found in heterogeneous landscapes that permit population persistence under very different regional climates through altitudinal shifts or changes in slope orientation (Hampe $\&$ Petit 2005). Finally, those regions of the world whose climatic conditions combine relative stability through time with heterogeneity in space tend to harbor not only disproportionately large concentrations of climate relicts, but also greater concentrations of endemic species (Fjeldså \& Lovett 1997, Qian \& Ricklefs 2000, Denk et al. 2001, Rodríguez-Sánchez et al. 2008). Such areas have been hypothesized to represent conservation hot spots but also critical areas for the generation of biodiversity (Fjeldså \& Lovett 1997, Hampe \& Petit 2005, Moore \& Donoghue 2007, Jansson \& Davies 2008).

According to our definition, climate relicts occur in areas with climatic conditions that have existed for an extended period and are currently rare within their surroundings ("relict climates," sensu Dobrowski 2011; see also Ohlemüller et al. 2008). This combination of characteristics arises from an important quality that determines the long-term suitability of refugia: their ability to decouple local climate trends from those occurring at regional scale. Such a decoupling
Refugium: area where species sustain populations during periods of environmental stress 


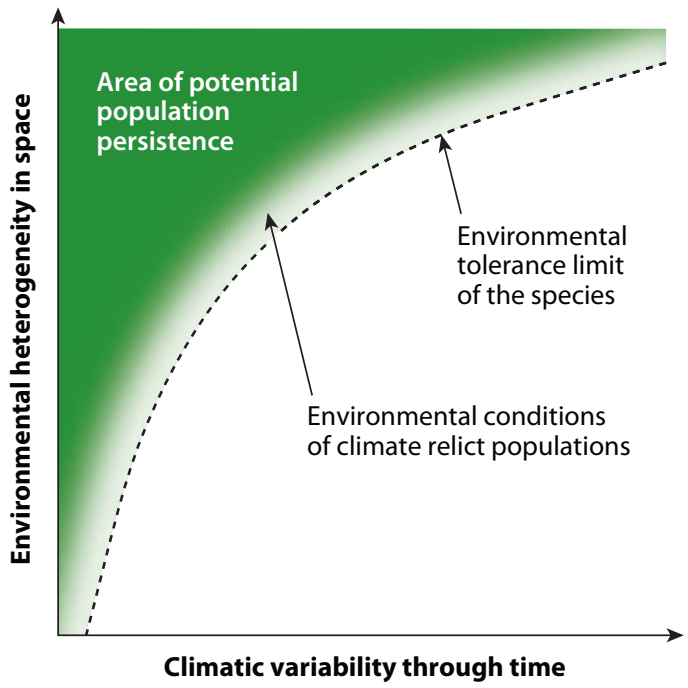

Figure 1

Conceptual model depicting the suitability of geographic areas for sustaining species under climate change as a function of spatiotemporal variability in environmental conditions. Geographic areas that permit the longterm persistence of populations can occur wherever landscape heterogeneity allows them to compensate for temporal variation in regional climate by enabling a species to move between different local microclimates.

arises as a consequence of topography (Dobrowski 2011), smaller-scale terrain effects (Pepin \& Lundquist 2008, Scherrer \& Körner 2010), edaphic particularities (Spitzer \& Danks 2006), or vegetation structure and physiognomy (Suggitt et al. 2011) and should generally help to decrease climatic variability within refugia (Dobrowski 2011). Because climate relict populations exist close to species' environmental tolerance limit, they depend on a low environmental stochasticity and, in particular, a low probability of experiencing extreme events (that is, episodes in which the acclimatory capacities of an organism are substantially exceeded) (Gutschick \& BassiriRad 2003). In the following, we briefly review landscape features that help mitigate variation in climate.

The actual role of topography in moderating regional advective climate is complex and its details are not fully understood (Dobrowski 2011). There is no doubt, however, that mountain topography can strongly affect local climate and generate steep climatic gradients. For instance, Dobrowski et al. (2009) found that 20-30\% of the temperature variation recorded over an 11-year period in the mountainous Lake Tahoe region (California, USA) could be attributed to spatial variance in physiognomic features. Several other authors have shown that mountain topography can generate temperature differentials within a few hundred meters to kilometers that approach or even exceed those temperature differences that mid-latitudes have experienced between the LGM and today (reviewed in Scherrer \& Körner 2010, Dobrowski 2011). This notion is fully in line with recent modeling work that compares current climatic conditions with those of the LGM and reveals their spatial congruence in many of the areas that presently house climate relict populations (Ohlemüller et al. 2011). However, relying on temperature alone to predict future species distributions in mountain ranges could oversimplify matters. Indeed, Crimmins et al. (2011) showed that many Californian mountain plants have experienced significant downward shifts in their optimum elevations through the past seven decades, most probably because they are tracking regional changes in climatic water balance rather than temperature. These authors predict 
that such trends could occur wherever future increases in water availability outpace evaporative demand.

Topography and related terrain effects are likely to be the major drivers in moderating regional variation of climate (Vanwalleghem \& Meentemeyer 2009). In fact, they appear to be almost indispensable for ensuring the persistence of pre-LGM relicts at temperate and higher latitudes. However, several phenomena at smaller spatial scales can likewise exert significant effects on local microclimate. For instance, water bodies such as springs, ravines, lakes, or mires represent widespread thermoregulators (Caissie 2006). Air temperatures in the center of a mire are usually somewhat below those measured in its surroundings and can temporarily fall $5-8^{\circ} \mathrm{C}$ below (Spitzer \& Danks 2006). Another, much rarer example of edaphic features providing cool microclimates is algific talus slopes in the vicinity of ice-filled caves (Nekola 1999). Finally, vegetation structure can exert an important effect on small-scale climatic variation. Thus, Thomas et al. (1999) observed in a heathland that an increment of just a few centimeters in vegetation height can reduce ground-level temperatures by $3-8^{\circ} \mathrm{C}$. Suggitt et al. (2011) compared three nearby vegetation types (broadleaf forest, heathland, and grassland) in a flat English landscape and recorded differences of more than $5^{\circ} \mathrm{C}$ in monthly temperature maxima and minima and of $10^{\circ} \mathrm{C}$ in thermal range. Generally, vegetation cover tends to reduce temperature extremes rather than modify temperature averages. The same is probably true for air and soil moisture (Holmgren et al. 1997; see also Ramírez et al. 2006, Rodríguez-Sánchez et al. 2008), for which positive effects of plant cover tend to become most evident in situations of drought.

\section{EFFECTS OF CURRENT CLIMATE ON THE PERFORMANCE OF RELICT POPULATIONS}

There is a limited but rapidly growing body of empirical evidence demonstrating that current climate constrains the reproduction and regeneration of relict populations. To date, most ecological research emphasizes the limiting effects of temperature and water balance (but see Pulido et al. 2008 for solar radiation). Both components are intrinsically linked and their respective influence is difficult to disentangle under field conditions. Moreover, the different drivers of recent climate change (warming, precipitation changes, $\mathrm{CO}_{2}$ increase, etc.) can influence organisms directly and indirectly through their effects on biotic interactions (Figure 2). This complexity represents a challenge for any study that attempts to reveal causal links between specific climatic trends and resulting population dynamics.

Unfortunately, empirical research on relicts currently shows a considerable bias toward certain study systems. A majority of studies deals either with plants (mostly woody species) or, to a lesser extent, insects (especially butterflies). Curiously, the latter group stands out for its rapid and pronounced response to changes in climate (Franco et al. 2006), whereas the former group is characterized by a great resilience (which does not preclude rapid microevolutionary changes) (Petit \& Hampe 2006). In addition, a large fraction of studies have been performed in mountain ranges located at mid- to low-temperate latitudes, commonly in regions with dry climate such as the Mediterranean Basin or southwestern North America. Markedly fewer investigations have been conducted on species inhabiting mires or arctic-alpine habitats, usually located at higher latitudes.

This caveat makes it difficult to derive general trends. However, the available evidence serves to illustrate that climate may affect population dynamics through diverse and sometimes unexpected paths. In the following, we briefly review how climate constrains the dynamics of relict populations, either directly or through its influence on biotic interactions. 

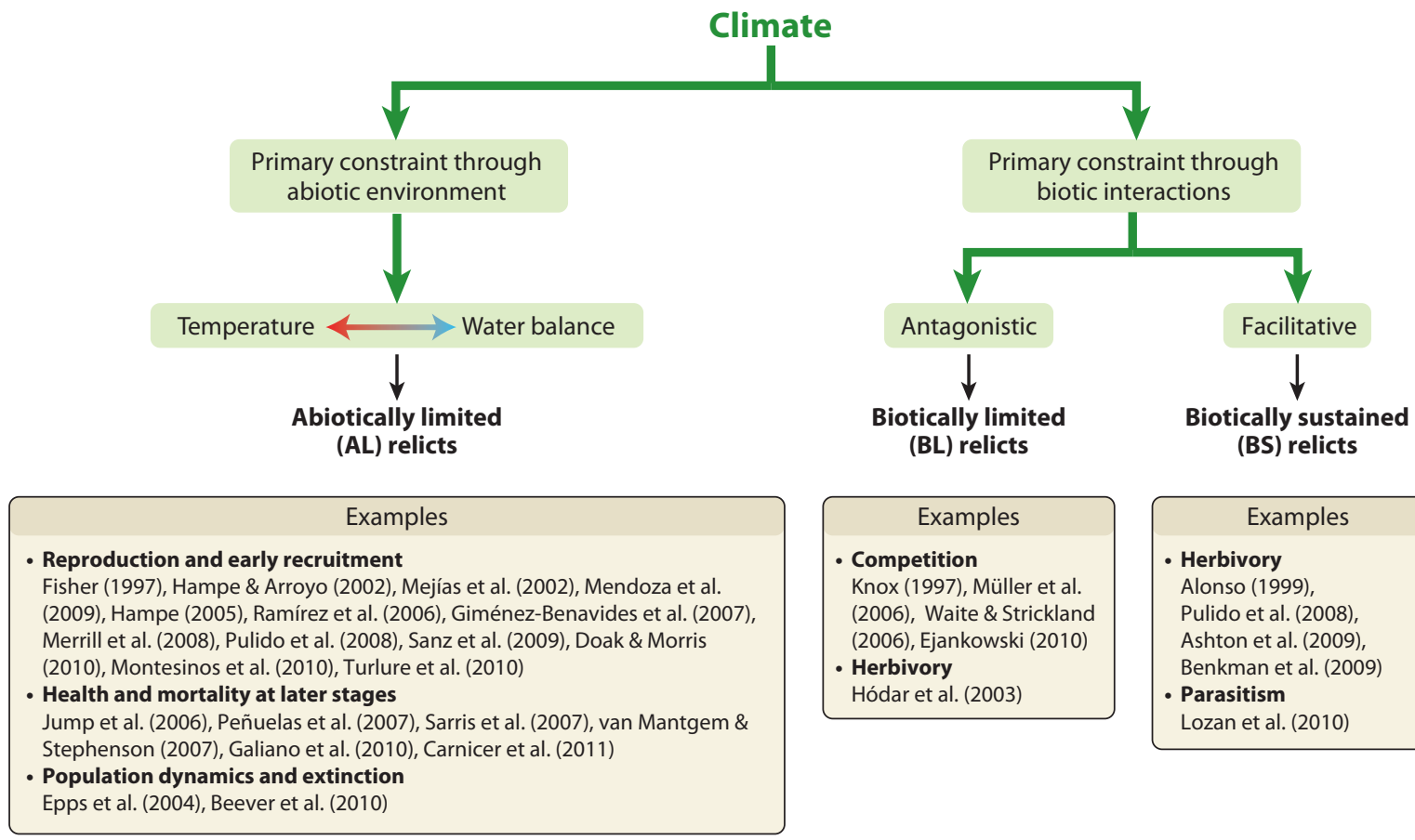

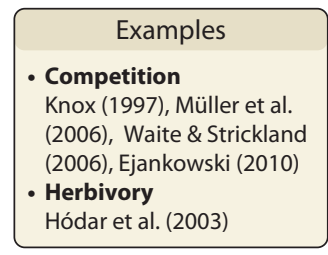

\begin{tabular}{|l|}
\hline \multicolumn{1}{|c|}{ Examples } \\
- Herbivory \\
Alonso (1999), \\
Pulido et al. (2008), \\
Ashton et al. (2009), \\
Benkman et al. (2009) \\
- Parasitism \\
Lozan et al. (2010)
\end{tabular}

Figure 2

Typology of climate relicts according to the key differences that are outlined in the text. The precise climatic limitation of individual, abiotically limited (AL) relicts will differ; the gradient between temperature and water balance is given as an example of such controls. Where biotic interactions form the primary constraint on relict populations, these can be classified as being restricted by antagonistic interactions [biotically limited (BL) relicts] or sustained by facilitative interactions [biotically sustained (BS) relicts]. References given as examples are discussed in the text.

\section{Evidence of Direct Climate Effects on Population Dynamics}

The regeneration niche describes the fundamental requirements for successful reproduction of species and is, therefore, often more relevant than the adult niche for assessing what determines the long-term viability of populations near their climatic tolerance limit (Jackson et al. 2009). Following this tenet, much empirical research on climate relicts has focused on the early stages of the life cycle. Most of these studies involve two approaches, either separately or in combination: (a) descriptive analyses of the habitat associations of recruitment success or mortality and/or (b) experimental manipulations of temperature or water balance. These investigations have shown that climate governs patterns of reproduction and recruitment in many relict populations.

Numerous plant ecological studies have highlighted climatic constraints on seed production (e.g., Fisher 1997, Hampe 2005, Giménez-Benavides et al. 2007, Montesinos et al. 2010) and early plant recruitment (e.g., Mejías et al. 2002; Ramírez et al. 2006; Pulido et al. 2008; Sanz et al. 2009, 2011). Many of these studies were performed in regions with seasonal water shortage; unsurprising then, water deficit was identified as an overwhelming cause of recruit mortality. An adequate water supply during the first year of establishment may enhance plant resistance to drought in subsequent years (Mendoza et al. 2009), a result that implies that even irregular wet years may enable long-lived species to sustain some regeneration. Interannual variation in early recruitment can impact later life stages; thus, Hampe \& Arroyo (2002) used dendrochronological 
data to show that the abundance of saplings in five relict populations of alder buckthorn (Frangula alnus) was positively related with the amount of precipitation in the year of their establishment.

Evidence from arctic-alpine plants is far less abundant. However, Doak \& Morris (2010) conducted a demographic study considering the entire life cycle of two perennial arctic-alpine herbs over a 10-year period. The authors showed that some life-cycle stages benefit from moderate temperature increases but all stages are negatively affected if temperature increases above a certain threshold. Demographic simulations suggest that populations could go extinct very quickly once temperatures reach such a "tipping point."

Patterns of early recruit survival are markedly less relevant than adult survival and fecundity for the population growth rate of long-lived species such as woody plants (Morris et al. 2008). Hence, short-term recruitment studies need to be complemented with other approaches such as studies of adult tree health and growth to infer long-term population trends and their relationship with climate. Continued growth declines have been observed and were related with elevated drought stress in several climate relict populations (e.g., Jump et al. 2006, Sarris et al. 2007). At a larger scale, analyses of climate-driven changes to long-term demographic patterns and forest dieback provide a means to investigate gradual or sudden shifts in the dynamics of tree populations and stands (Peñuelas et al. 2007, van Mantgem \& Stephenson 2007, Allen et al. 2010, Galiano et al. 2010, Carnicer et al. 2011). Such accounts can provide valuable background information about the role of extreme events versus gradual deterioration of climate for the dynamics and extinction of relicts.

Direct climate effects on animal relicts have been demonstrated in two studies of butterfly species in Spanish mountain ranges that found that air temperature tends to affect patterns of oviposition and egg survival as well as the habitat use and survival of caterpillars (Merrill et al. 2008, Ashton et al. 2009). Such trends are not limited to relatively warm and dry environments. For instance, Turlure et al. (2010) showed experimentally that even weak increases in temperature (i.e., well within the range of differentials measured between nearby microhabitats) can also reduce the survival of caterpillars of the cranberry fritillary (Boloria aquilonaris) that inhabit cool and watersaturated habitats such as mires. Similarly, Popescu \& Gibbs (2009) found that pond occupancy by mink frogs (Rana septentrionalis) at the species' southern range margin in northeastern North America was limited by water temperature during embryo development.

Finally, evidence for climate effects in recent extinctions of relict populations comes from two mammal species. Epps et al. (2004) analyzed records of historical population extinctions in desert bighorn sheep (Ovis canadensis) to show that these were related with water availability. Beever et al. (2010) also used such historical extinction records for American pikas (Ochotona princeps) and observed that patterns of extinction were in agreement with predictions based on temperature stress. These two studies stand out as rare attempts to address a key question that possibly represents the greatest challenge for research on the fate of climate relicts: How deterministic are climate-driven population extinctions?

\section{Climate and Biotic Interactions}

A widely held tenet in ecological biogeography predicts that the high-latitude or altitude range limit of species should be primarily controlled by abiotic factors whereas the opposite limit should be primarily determined by biotic interactions (Brown et al. 1996, Ackerly 2003). There is good support for the former hypothesis (Normand et al. 2009), whereas the paucity of empirical data has so far hampered attempts to address the latter. However, the evidence described in the previous section clearly challenges the view that biotic interactions generally prevail as determinants of low-latitude and altitude range limits. 
Abiotically limited (AL) climate relict: primarily constrained by climate-driven abiotic factors

Facilitation: species interaction that benefits at least one of the participants and causes harm to neither

Biotically limited (BL) climate relict: restricted to areas that are inaccessible to antagonistic species for climatic reasons

Biotically sustained (BS) climate relict: requires a host or mutualist that is itself limited by climate
Instead, we believe that most climate relicts can be assigned to one of three types with regard to their abiotic and biotic environment (Figure 2): (a) Abiotically limited relicts (AL relicts) have their distribution and performance primarily constrained by abiotic factors related with climate, such as high temperatures or water deficit. Such relicts can benefit from biotic interactions if these help mitigate environmental conditions (most notably through facilitation). Recent climate change should have immediate negative consequences for such relicts if it continues per past climatic trends. (b) Biotically limited relicts (BL relicts) are able to persist in areas that are not accessible to antagonistic species for climatic reasons (such as low temperatures, lack or overabundance of water, or wind). This ability protects them against competitors (Knox 1997, Waite \& Strickland 2006, Ejankowski 2010), herbivores (Hódar et al. 2003), and other interactors that may put populations at risk. Typical habitats that harbor relicts of this type are mires, rocky outcrops, or grasslands above the tree line. Recent climate change may temporarily improve the performance of such populations but also increases their risk of being suppressed by their antagonists. (c) Biotically sustained relicts (BS relicts) require for their persistence a host or mutualist that is limited by climate. This relict type is likely to be less common than the other two types, yet some examples have been described [host plants for herbivores (Alonso 1999, Spitzer \& Danks 2006, Merrill et al. 2008), hosts of insect parasites (Lozan et al. 2010), plants needed by seed predators (Benkman et al. 2009 and references therein); we are not aware of published examples relating to mutualists]. In the following, we briefly discuss the role of some biotic interactions for the population dynamics of different relict types.

Facilitation. The importance of facilitation tends to increase as environments become more stressful (Holmgren et al. 1997), so it should be a widespread phenomenon in AL relicts. Indeed, numerous studies in semiarid regions have shown that successful recruitment of relict plants often relies heavily on facilitation by nurse plants (e.g., Castro et al. 2004, Ramírez et al. 2006, ValienteBanuet et al. 2006). Examples of facilitation are, however, not limited to dry climates and habitats. Turlure et al. (2010) showed that Sphagnum hummocks tend to facilitate larval survival of the mire specialist butterfly $B$. aquilonaris by attenuating daily fluctuations in ambient temperature. Spitzer \& Danks (2006) list further examples of insects that benefit from facilitation by Sphagnum. Turlure et al. (2009) highlight that such subtle phenomena can have important implications for conservation but will escape identification unless the functional habitats of species are properly analyzed.

Competition. Interspecific competition is often seen as a (if not the) major biotic driver in the retraction of species' low-latitudinal range margins (e.g., Brown et al. 1996, Ackerly 2003). However, its actual role in the extirpation of relict populations is not always easy to establish as incoming species may simply benefit from the retreat of the formerly dominant species without exacerbating it themselves (cf. Peñuelas et al. 2007, Allen et al. 2010, Galiano et al. 2010). The most important phenomenon related to interspecific competition is probably the transformation of refugial habitats by vegetation. The colonization of treeless areas by woody plants is an obvious example (Müller et al. 2006, Spitzer \& Danks 2006), yet competitive interactions can be considerably more subtle (Knox 1997, Ejankowski 2010). A striking example of competition between vertebrates and microorganisms concerns gray jay (Perisoreus canadensis) populations in southeastern Ontario (Waite \& Strickland 2006). Rising autumn temperatures in this area cause increasing rot of cached reserves of perishable food that birds require for rearing their offspring, thus compromising the reproductive success of populations.

Climate relicts should generally be at a competitive disadvantage as they either perform close to their tolerance limit (in the case of AL relicts) or have adapted to habitats that are characterized 
by low competitive pressure (many BL relicts). This hypothesis is corroborated by the relatively few empirical accounts available (Knox 1997, Müller et al. 2006, Turlure et al. 2009, Ejankowski 2010). Finally, the work of Linares et al. (2010a) deserves a special mention for its emphasis on intraspecific competition in climate relicts. Using tree ring analyses, these authors showed that competition can significantly influence individuals' susceptibility to climate-related stress and resulting growth decline in Spanish fir (Abies pinsapo).

Parasitism and pathogens. The particular situation of climate relicts implies a disadvantage and an advantage concerning the antagonistic interactions they experience. On the one hand, their stressful abiotic environment renders them particularly susceptible to attacks (Gutschick \& BassiriRad 2003, Allen et al. 2010). Interactions between abiotic and biotic stressors are reciprocal and should further exacerbate their already precarious situation (Hódar et al. 2003, Sthultz et al. 2009, Linares et al. 2010b). On the other hand, the geographical isolation and small size of relict populations should make it more difficult for parasites or pathogens to detect them and to sustain permanent populations on them (Kawecki 2008, Gibson et al. 2010); this failure would result in a generally lower infection load of relicts. Indeed, Turlure et al. (2010) did not find a single parasite on several hundred caterpillars of B. aquilonaris, considering this an "unusually low parasitoid load for a butterfly" (p. 1890). In addition, experimental evidence indicates that the virulence of pathogens tends to decrease in small and isolated populations (Boots \& Mealor 2007).

Other interactions affecting relict persistence. Climate change is commonly predicted to represent a particular risk for those species that rely on other organisms to complete their life cycle (Parmesan 2006), such as BS relicts. This risk appears likely for specialists such as monophagous insects (Alonso 1999), birds (Benkman et al. 2009), or parasites (Lozan et al. 2010). Merrill et al. (2008) reported that food plant availability determines the current high-altitude range limit of the specialist black-veined white butterfly (Aporia crataegi), indicating that this species may run into trouble under future warming if populations of its food plants (hawthorn, Crataegus spp., and blackthorn, Prunus spinosa) shift their altitudinal range more slowly than the butterfly. On the contrary, Ashton et al. (2009) reported that relict populations of the mountain apollo (Parnassius apollo) living at different altitudes readily switched between various closely related host plants according to their local abundance.

Remarkably little empirical evidence exists about mutualistic interactions such as pollination or seed dispersal in relict populations. Hampe (2005) observed that a temporal mismatch between flower anthesis and maximum pollinator activity limited successful seed set in $F$. alnus for a brief period near the end of the flowering season. As a consequence, annual seed production in these populations is highly susceptible to adverse weather conditions during this period. Similar mismatches could be a relatively common phenomenon given the quick and pronounced response of many insects to changes in climate. Their impact should depend on the resilience of relict plants to changes in pollinator density, the availability of alternative pollinators, and plants' ability to self-pollinate (Bond 1994).

\section{SPECIES FEATURES FAVORING PERSISTENCE}

The geographical distribution of relict populations and their persistence close to their climatic tolerance limit have some important implications for their demography and genetics (see also Kawecki 2008): (a) Populations, at least those that are primarily constrained by abiotic factors (i.e., AL relicts), must survive environmental conditions that can temporarily approach or exceed their physiological tolerance. (b) Populations have to maintain a stable long-term population growth rate despite irregular regeneration. (c) Populations have to perform within a habitat whose restricted 
Carrying capacity: population size that a species can sustain within a given environment size limits their carrying capacity and under a degree of isolation that limits opportunities for longdistance gene flow or demographic rescue through metapopulation dynamics. The mechanisms by which individual species cope with these constraints differ to some extent between plants and animals. In the following, we briefly discuss features or strategies that help relict populations persist in their particular circumstances.

\section{Ability to Escape, Endure, or Recover from Episodes of Peak Stress}

Even though regional climatic variability is mitigated within refugia, relict populations are likely to experience episodes in which the acclimatory capacities of organisms are exceeded. The primary strategy of animals consists in escaping from such situations through thermoregulatory movements toward more favorable microhabitats (Feder et al. 2009). A multitude of case studies report such compensatory behavior, including in several climate relicts (Merrill et al. 2008, Ashton et al. 2009, Beever et al. 2010, Turlure et al. 2009, 2010). Plants cannot escape situations of great environmental stress, but different morphological adaptations (e.g., cushion growth, lignotubers, deep root system), and physiological adaptations (e.g., mechanisms enhancing production of stress hormones and stomatal closure) can reduce their negative impact. Moreover, a high capacity for indeterminate (or clonal) growth allows individuals to respond plastically to biomass losses, modify biomass allocation, and construct foliage that is acclimated to prevailing conditions (Ninemets 2010). A high capacity for storing nonstructural carbon enhances resprouting after the loss of biomass and enables individuals to quickly regain lost canopy space. Finally, a permanent seed bank can also help a species to escape from adverse environmental conditions, although it implies a competitive disadvantage compared with other species that persist as established plants.

\section{Long Lifespan and Nonsexual Propagation}

Recruitment failure is a common phenomenon in climate relicts. Under stressful environmental conditions, only alleviated in particularly favorable years, successful regeneration can be best achieved through a long lifespan combined with iterated reproduction. Moreover, life histories based on high adult survival reduce the susceptibility of populations to demographic bottlenecks arising from environmental stochasticity (Morris et al. 2008), while the resulting generation overlap increases the number of potential mates (and thus effective population size). Although an extended lifespan is beneficial for both plants and animals, it confers additional advantages to many plant species. Because these species grow more or less continuously throughout their life, a longer life implies a greater size and fecundity, which allows individuals to maximize their reproductive output during the rare opportunities for successful recruitment (Petit \& Hampe 2006).

In addition, many plants and animals can rely on nonsexual propagation during episodes when sexual reproduction is precluded by environmental conditions (Eriksson 2000). Kawecki (2008) lists numerous examples_including algae, flowering plants, flatworms, crustaceans, insects, mollusks, fishes, and reptiles_-in which clonal forms tend to be prevalent in marginal habitats, "in particular those whose marginal nature is due to abiotic factors" (p. 335). Interestingly, most of these asexual forms are polyploid or of hybrid origin, which led Kawecki (2008) to argue that polyploidization and hybridization may represent underappreciated catalyzers in terms of the capacity of populations to persist under adverse environmental conditions.

\section{Ability to Persist in Isolated Populations with Low Carrying Capacity}

Climate relicts are, by definition, confined to small enclaves with very few opportunities for interchange between populations from different refugia. Their long-term persistence in such a 
situation has usually resulted in genetic depauperation (Hampe \& Petit 2005). Moreover, low and unpredictable recruitment rates exacerbate the importance of effective mating during the rare opportunities for successful reproduction. Population persistence should, therefore, benefit from strategies that maximize effective population size and minimize Allee effects and inbreeding depression within the limits imposed by the reduced size of the refugium. These include mechanisms promoting reproductive insurance (e.g., self-compatibility, great fecundity) and the connectivity of potential mates (e.g., active mate-location behavior, directional pollen flow). Moreover, many plants are able to compensate high risks of pollination or dispersal failure by complementary demographic strategies (Bond 1994). By contrast, maximizing population size represents a particular challenge for BS relicts, which should tend to exploit relatively abundant and resilient hosts (such as woody plants) (Alonso 1999, Merrill et al. 2008, Benkman et al. 2009).

The ability of populations to persist over extended periods in a difficult environment thus depends to a large extent on species' characteristics and life-history strategies. A sound (and ideally mechanistic) understanding of how these attributes trigger population dynamics should greatly help with evaluating the vulnerability of extant climate relicts and developing appropriate, context-guided conservation measures.

\section{FUTURE THREATS}

The continued persistence of climate relicts is at odds with the pessimistic predictions of many model-based analyses of climate-driven range changes. The apparent contradiction arises, among other factors, because current species distribution models lack the spatial and biological detail required to predict the persistence of populations at the local level, where fine-scale variation in landscape characteristics can buffer climates against change or provide alternative potential habitats (Thuiller et al. 2008, Willis \& Baghwat 2009). The favorable effect of landscape heterogeneity on the historical long-term viability of relict populations highlights that future global warming does not necessarily doom climate relict populations to extinction. However, such populations are undeniably in a precarious situation and, hence, particularly susceptible to threats from warming and other drivers of global change.

The current trend of rapidly rising global temperatures is now well established, and $\mathrm{CO}_{2}$ emissions continue to rise faster than in the most pessimistic Intergovernmental Panel on Climate Change scenario (Le Quere et al. 2009). High latitudes are predicted to experience the strongest warming with annual mean temperature possibly rising up to $8^{\circ} \mathrm{C}$ by 2100 , although many temperate regions may expect increments between 2 and $5^{\circ} \mathrm{C}$ (IPCC 2007). Hence, future broad-scale warming may relatively soon exceed small-scale temperature differentials in all but the most heterogeneous landscapes.

Although changes in precipitation are less easy to predict than those of temperature, it appears likely that precipitation will increase in many high-latitude areas but decrease in many warm temperate and subtropical regions (IPCC 2007). The global trends of temperature and precipitation and the greater spatial variability in precipitation trends also imply that not all regions that will become warmer will inevitably become dryer and more inhospitable. Instead, some regions could maintain benign conditions and possibly even extend their role as centers of climate relict diversity in a world of rapid change (Crimmins et al. 2011).

The uncertainties about direct effects of future climate change are further exacerbated by diverse associated processes. For instance, rising $\mathrm{CO}_{2}$ concentrations can lead to elevated plant growth through a combination of increased photosynthesis and water-use efficiency (Poorter \& Navas 2003). This implies that AL relict plants threatened by increasing drought stress could benefit from rising $\mathrm{CO}_{2}$ levels, whereas $\mathrm{BL}$ relicts could be compromised by resulting changes 
Phenotypic plasticity: ability of an organism to change its phenotype in response to environmental changes in vegetation structure. More generally, the effects of future climate change on the alteration of biotic interactions represent perhaps the greatest source of uncertainty for the prospects of climate relicts. Whereas AL relicts appear most concerned by unspecific interactions such as facilitation and may, therefore, be relatively flexible, BL relicts and even more BS relicts may be heavily impacted by climate-driven changes in their relationship with other species (e.g., Hódar et al. 2003, Waite \& Strickland 2006, Merrill et al. 2008). Finally, even AL relicts can be threatened by novel or reinforced interactions that further compromise their performance in an already stressful environment (e.g., Linares et al. 2010a, 2010b).

Although climate change affects the prospects of climate relicts, it often represents a less immediate threat than more direct anthropogenic impacts. Indeed, direct human extirpation of populations through landscape transformation remains a likely major cause of the extinction of climate relict populations. Within arid regions, AL relicts are typically concentrated in relatively benign and humid mountainous landscapes that are of great (and further increasing) potential value for socioeconomic activities such as horticulture, forestry, livestock husbandry, storage of water reserves for irrigation, tourism, etc. For instance, Médail \& Diadema (2009) assessed the distribution of refugia in the Mediterranean Basin and found that $25 \%$ of the area identified as past refugia coincides with areas of peak human density within the region. In more humid regions, climate relicts (especially of the BL type) often persist in relatively unproductive ecosystems such as mires or wetlands that are frequently at high risk of being drained and transformed into plantation forestry or agricultural lands (Spitzer \& Danks 2006).

\section{POTENTIAL RESPONSES}

Climate relicts have limited opportunities for migrating to alternative favorable sites as climate warms, even though heterogeneous landscapes can provide relatively abundant opportunities for retreat (Dobrowski 2011). Alternatively, relict populations can improve their prospects by enlarging their climatic tolerance through phenotypic plasticity or microevolutionary adaptation (Reed et al. 2011). If both migration and adaptive responses fail, and current refugia cease to provide suitable environmental conditions for species persistence, then population extinction becomes the most likely scenario.

\section{Phenotypic Plasticity and Microevolutionary Adaptation}

Phenotypic plasticity can enable populations to tolerate environmental changes, either directly through phenotypic adjustments during individuals' lifetime or indirectly by reducing negative consequences of strong selection pressures on population growth rates (Morris et al. 2008, Niinemets 2010, Pfennig et al. 2010). Both effects should be highly relevant for AL relicts as they should help these relics endure episodes of peak stress and minimize negative effects of demographic stochasticity. BL and BS relicts clearly benefit from the second effect, because phenotypic plasticity is expected to reduce mortality associated with strong selection pressures in all species subject to rapid environmental changes (Reed et al. 2011). However, the role of phenotypic plasticity in allowing BL and BS relicts to tolerate environmental change directly is less straightforward because, by definition, other organisms will strongly modify their response to change.

Phenotypic plasticity allows populations to track changing conditions without significant adaptation taking place. However, once the capacity for phenotypic adjustment is exceeded, then genetic adaptation remains the only option. An important question is, therefore, whether a high potential for phenotypic plasticity could hamper microevolutionary processes required to persist in a rapidly changing environment. Although this question does not have a simple answer 
(Reed et al. 2011), it is notable that phenotypic plasticity can facilitate microevolution by exposing previously "hidden" genetic variation to selection if a plastic response to novel conditions is possible (Pfennig et al. 2010). Consequently, populations may adapt by promoting specialist genotypes suited for the novel conditions as well as by modifying the limits of phenotypic plasticity.

Any microevolutionary response to selection requires that populations contain sufficient additive genetic variation for relevant adaptive traits and that adaptation is not hampered by genetic, functional, or developmental constraints that make new phenotypes either difficult to express or very costly (e.g., due to pleiotropy or epistasis) (Kawecki 2008, Reed et al. 2011). Assuming these conditions are met, genetic adaptation can take place on an ecologically relevant timescale in response to climatic and other environmental changes from standing genetic variation (Jump \& Peñuelas 2005, Bradshaw \& Holzapfel 2006). However, several characteristics of relict populations imply that their potential for microevolutionary adaptation may be limited. First, strong phenotypic divergence compared with conspecifics from other parts of the range does not appear to be a common phenomenon despite the presumable long-term exposure of relict populations to relatively strong selective pressures (but see, e.g., Hampe \& Bairlein 2000, Benkman et al. 2009). This notion is in line with the observation that species niches often remain notably stable over extended periods (Ackerly 2003). However, potential physiological divergence of relict populations is less well studied and deserves further investigation given such potentially strong selection pressures (Hofmann \& Todgham 2010). Second, within-population genetic variation tends to be low in many climate relicts as a consequence of small population size and past bottlenecks (Hampe $\&$ Petit 2005). Note, however, that low diversity at neutral molecular markers does not automatically imply that populations are also genetically depauperate for variation in ecologically relevant traits (Kawecki 2008). Third, the small size of many relict populations, in combination with strong selection pressure, is likely to elevate substantially their risk of extinction due to demographic or environmental stochasticity before they can effectively adapt (Hoffmann \& Willi 2008, Bell \& González 2009).

\section{Extinction}

Although broad-scale changes in species distributions can reasonably be forecast (Thuiller et al. 2008), our understanding of the environment and ecology of most climate relicts remains too poor to adequately anticipate their persistence or demise. The historical resilience of such populations demonstrates that we cannot simply assume that they will be extirpated soon. However, climatic changes currently under way-particularly the increasing frequency of extreme climatic events (IPCC 2007) —are likely to increase the risk of extinction in many marginal populations. In some cases, existing environments may continue to buffer against climatic changes (Dobrowski 2011) and demographic and evolutionary pressures on resident populations may remain substantially unchanged, whereas other populations may suffer rapid decline as abiotic or biotic conditions change. Dynamics of extinction will, moreover, differ between relict types. AL relicts are likely to suffer rapid decline if the climatic conditions limiting population growth deteriorate, whereas the fates of BL and BS relicts are less straightforward and predictable. Finally, direct anthropogenic extirpation remains probably the most serious threat for many climate relicts, because this form of extinction will be the most rapid, least reversible, and least discriminating of all.

\section{CONCLUSIONS AND PROSPECTS}

We are only beginning to understand the particular character, history, and ecological requirements of climate relicts. Their study can teach us much about the responses of species to climate change. 
How are natural populations affected by the different components of climate change? What role do extreme climatic events play? To what extent can heterogeneous landscapes help mitigate future climate change? What can we do to anticipate and possibly mitigate population declines? And, ultimately, how deterministic and "unavoidable" are climate-driven extinction processes? Climate relicts represent extremely well-suited models for addressing these key questions concerning the impacts of future climate change on biodiversity.

By contrast, recent research is demonstrating that the current scientific debate about retreating range limits is burdened with many simplistic notions that do little justice to the great diversity of mechanisms and processes that take place in marginal populations. Although there is no doubt that recent climate change exacerbates the precarious situation of many relicts and can even drive them to extinction, the accumulating evidence also highlights that its effects can be understood only if we appropriately consider both the abiotic and biotic environments in which these populations occur. Indeed, climate is often not the most immediate threat to the existence of climate relicts. Hence, there are chances that we may, at least to some extent, be able to ensure the continued persistence of climate relicts in a warmer world.

\section{SUMMARY POINTS}

1. Many temperate and higher-latitude species worldwide have climate relict populations. These persist in areas where settings contribute to decouple local microclimates from regional trends and mitigate the impact of extreme climatic events.

2. Climate relicts have persisted despite episodes of great stress, irregular recruitment, and a low carrying capacity imposed by their habitat. The mechanisms to cope with these constraints differ partly between plants and animals because of differences in their growth strategies, trophic level, and mobility.

3. Climate governs the dynamics of relict populations either directly or indirectly through its influence on biotic interactions. Three major types of relicts can be identified according to their relationship with their abiotic and biotic environment: $(a)$ those primarily constrained by climate-driven abiotic factors, $(b)$ those restricted to areas that are not accessible to antagonistic species, and $(c)$ those requiring a host or mutualist that is limited by climate.

4. Although future climate change represents an undeniable threat for the continued existence of many climate relicts, other drivers of global change (in particular, changed land use) may represent even more immediate causes of population extinction.

5. An improved knowledge of how climate relict populations are formed and maintained will substantially increase our understanding of the likely impacts of climate change on species distributions and our ability to conserve those populations that are most at risk.

\section{FUTURE ISSUES}

1. Future empirical work needs to overcome the existing strong taxonomic and geographical bias to derive general principles and to evaluate how transferable results from individual relicts are across biological systems that are intrinsically idiosyncratic. 
2. Studies need to pursue a stronger integration of demographic, physiological, and molecular data with modeling exercises to advance our mechanistic understanding of population performance under marginal conditions and its evolutionary implications.

3. The influence of climate on relict populations cannot be understood without an appropriate consideration of their biotic as well as abiotic environments. Studies need to address how climate mediates biotic interactions both within and between species.

4. Understanding of environmental conditions facilitating the persistence of climate relicts should be integrated into regional species distribution models in an attempt to increase both their accuracy and resolution.

\section{DISCLOSURE STATEMENT}

The authors are not aware of any affiliations, memberships, funding, or financial holding that might be perceived as affecting the objectivity of this review.

\section{ACKNOWLEDGMENTS}

A.H. is currently affiliated with INRA, UMR 1202 Biodiversity Genes and Communities, 33612 Cestas Cedex, France and the University of Bordeaux, UMR 1202 Biodiversity Genes and Communities, F-33400 Talence, France. We are indebted to Bill Jamieson for preparing the figures and Begoña Garrido for her logistic support. Insightful comments from Pedro Jordano, Josep Peñuelas, Rémy Petit, Fernando Pulido, Francisco Rodríguez-Sánchez, and Sharon Strauss helped improve a previous manuscript version. Manuscript elaboration benefitted from European Union grant MERG-CT-2007-208108 and Ministerio de Ciencia e Innovación grants RYC-2008-02603 and CGL2010-18381 to A.H. and from Natural Environment Research Council grant NE/G002118/1 and a Carnegie Research grant to A.S.J.

\section{LITERATURE CITED}

Ackerly DD. 2003. Community assembly, niche conservatism, and adaptive evolution in changing environments. Int. F. Plant Sci. 164:S165-84

Allen CD, Macalady AK, Chenchouni H, Bachelet D, McDowel N, Vennetier M, et al. 2010. A global overview of drought and heat-induced tree mortality reveals emerging climate change risks for forests. For. Ecol. Manage. 259:660-84

Alonso MC. 1999. Variation in herbivory by Yponomeuta mahalebella on its only host plant Prunus mahaleb along an elevational gradient. Ecol. Entomol. 24:371-79

Ashton S, Gutiérrez D, Wilson RJ. 2009. Effects of temperature and elevation on habitat use by a rare mountain butterfly: implications for species responses to climate change. Ecol. Entomol. 34:437-46

Beever EA, Ray C, Mote PW, Wilkening JL. 2010. Testing alternative models of climate-mediated extirpations. Ecol. Appl. 20:164-78

Bell G, Gonzalez A. 2009. Evolutionary rescue can prevent extinction following environmental change. Ecol. Lett. 12: 942-48

Benkman CW, Smith JW, Keenan PC, Parchman TL, Santisteban L. 2009. A new species of the red crossbill (Fringillidae: Loxia) from Idaho. Condor 111:169-76

Bennett KD, Provan J. 2008. What do we mean by "refugia"? Quat. Sci. Rev. 27:2449-55

Bond WJ. 1994. Do mutualisms matter? Assessing the impact of pollinator and disperser disruption on plant extinction. Phil. Trans. R. Soc. London Ser. B 344:83-90

Boots M, Mealor M. 2007. Local interactions select for lower pathogen infectivity. Science 315:1284-86 
Demonstrates that species distributions can expand at their low altitude/latitude limits if local precipitation changes render water balance more favorable.

Long-term demographic study showing how increasing environmental stress may be masked by demographic compensation until a point where rapid population extinction is likely to occur.

(Dubrowski 2011)

Illustrates the importance of landscape physiography in shaping local microclimates.
Bradshaw WE, Holzapfel CM. 2006. Evolutionary response to rapid climate change. Science 312:1477-78 Brown JH. 1971. Mammals on mountains: nonequilibrium insular biogeography. Am. Nat. 105:467-78

Brown JH, Stevens GC, Kaufman DM. 1996. The geographic range: size, shape, boundaries, and internal structure. Annu. Rev. Ecol. Syst. 27:597-623

Cain SA. 1930. Certain floristic affinities of the trees and shrubs of the Great Smoky Mountains and vicinity. Butler Univ. Bot. Stud. 1:129-50

Caissie D. 2006. The thermal regime of rivers: a review. Freshw. Biol. 51:1389-406

Calleja JA, Benito Garzón M, Sainz Ollero H. 2009. A Quaternary perspective on the conservation prospects of the Tertiary relict tree Prunus lusitanica L. F. Biogeogr. 36:487-98

Carnicer J, Coll M, Ninyerola M, Pons X, Sánchez G, Peñuelas J. 2011. Widespread crown condition decline, food web disruption, and amplified tree mortality with increased climate change-type drought. Proc. Natl. Acad. Sci. USA 108:1474-78

Castro J, Zamora R, Hódar JA, Gómez JM. 2004. Seedling establishment of a boreal tree species (Pinus sylvestris) at its southernmost distribution limit: consequences of being in a marginal Mediterranean habitat. 7. Ecol. 92:266-77

Cox CB, Moore PD. 2010. Biogeography: an Ecological and Evolutionary Approach. New York: John Wiley \& Sons. 506 pp. 8th ed.

Crimmins SM, Dobrowski SZ, Greenberg JA, Abatzoglou JT, Mynsberge AR. 2011. Changes in climatic water balance drive downhill shifts in plant species' optimum elevations. Science 331:32427

Crochet PA, Chaline O, Surget-Groba Y, Debain C, Cheylana M. 2004. Speciation in mountains: phylogeography and phylogeny of the rock lizards genus Iberolacerta (Reptilia: Lacertidae). Mol. Phylogen. Evol. 30:860-66

Danin A. 1999. Desert rocks as plant refugia in the Near East. Bot. Rev. 65:93-170

Davis MB, Shaw RG, Etterson JR. 2005. Evolutionary responses to a changing climate. Ecology 86:1704-14

Denk T, Frotzler N, Davitashvili N. 2001. Vegetational patterns and distribution of relict taxa in humid temperate forests and wetlands of Georgia (Transcaucasia). Biol. 7. Linn. Soc. 72:287-332

Doak DF, Morris WM. 2010. Demographic compensation and tipping points in climate-induced range shifts. Nature 467:959-62

Dobrowski SZ. 2011. A climatic basis for microrefugia: the influence of terrain on climate. Glob. Change Biol. 17:1022-35

Dobrowski SZ, Abatzoglou J, Greenberg JA, Schladow G. 2009. How much influence does landscape-scale physiography have on air temperature in a mountain environment? Agric. For. Meteorol. 149:1751-58

Ejankowski W. 2010. Demographic variation of dwarf birch (Betula nana) in communities dominated by Ledum palustre and Vaccinium uliginosum. Biologia 65:248-53

Epps CW, McCullough DR, Wehausen JD, Bleich VC, Rechel JL. 2004. Effects of climate change on population persistence of desert-dwelling mountain sheep in California. Conserv. Biol. 18:102-13

Eriksson O. 2000. Functional roles of remnant plant populations in communities and ecosystems. Glob. Ecol. Biogeogr. 9:443-49

Feder ME, Garland T Jr, Marden JH, Zera AJ. 2009. Locomotion in response to shifting climate zones: not so fast. Annu. Rev. Physiol. 72:167-90

Fisher M. 1997. Decline in the juniper woodlands of Raydah reserve in southwestern Saudi Arabia: a response to climate changes? Glob Ecol. Biogeogr. Lett. 6:379-86

Fjeldså J. Lovett JC. 1997. Biodiversity and environmental stability. Biodiv. Conserv. 6:315-23

Franco AMA, Hill JK, Kitschke C, Collingham YC, Roy DB, et al. 2006. Impacts of climate warming and habitat loss on extinctions at species' low-latitude range boundaries. Glob. Change Biol. 12:1545-53

Galiano L, Martínez-Vilalta J, Lloret F. 2010. Drought-induced multifactor decline of Scots pine in the Pyrenees and potential vegetation change by the expansion of co-occurring oak species. Ecosystems 13:978 91

Gibson AK, Mena-Ali JI, Hood ME. 2010. Loss of pathogens in threatened plant species. Oikos 119:1919-28

Giménez-Benavides L, Escudero A, Iriondo JM. 2007. Reproductive limits of a late-flowering high-mountain Mediterranean plant along an elevational climate gradient. New Phytol. 173:367-82 
Gorchakovskii PL, Zolotareva NV. 2006. Phytodiversity of relict steppe enclaves in the Urals: experience in comparative assessment. Russ. F. Ecol. 37:378-86

Gutschick VP, BassiriRad H. 2003. Extreme events as shaping physiology, ecology, and evolution of plants: toward a unified definition and evaluation of their consequences. New Phytol. 160:21-42

Hampe A. 2005. Fecundity limits in Frangula alnus (Rhamnaceae) relict populations at the species' southern range margin. Oecologia 143:377-86

Hampe A, Arroyo J. 2002. Recruitment and regeneration in populations of an endangered South Iberian Tertiary relict tree. Biol. Conserv. 107:263-71

Hampe A, Bairlein F. 2000. Modified dispersal-related traits in disjunct populations of bird-dispersed Frangula alnus (Rhamnaceae): a result of its Quaternary distribution shifts? Ecography 23:603-13

Hampe A, Petit RJ. 2005. Conserving biodiversity under climate change: the rear edge matters. Ecol. Lett. 8:461-67

Hódar JA, Castro J, Zamora R. 2003. Pine processionary caterpillar Thaumetopoea pityocampa as a new threat for relict Mediterranean Scots pine forests under climatic warming. Biol. Conserv. 110:123-29

Hoffmann AA, Willi Y. 2008. Detecting genetic responses to environmental change. Nat. Rev. Genet. 9:421-32

Hofmann GE, Todgham AE. 2010. Living in the now: physiological mechanisms to tolerate a rapidly changing environment. Annu. Rev. Physiol. 72:127-45

Holmgren M, Scheffer M, Huston MA. 1997. The interplay of facilitation and competition in plant communities. Ecology 78:1966-75

Horsak M, Chytry M, Pokryszko BM, Danihelka J, Ermakov N, et al. 2010. Habitats of relict terrestrial snails in southern Siberia: lessons for the reconstruction of palaeoenvironments of full-glacial Europe. 7. Biogeogr. 37:1450-62

IPCC. 2007. Climate Change 2007: The Physical Science Basis. Cambridge, MA: Cambridge Univ. Press. 996 pp.

Jackson ST, Betancourt JL, Booth RK, Gray ST. 2009. Ecology and the ratchet of events: climate variability, niche dimensions, and species distribution. Proc. Natl. Acad. Sci. USA 106:S19685-92

Jansson R, Davies TJ. 2008. Global variation in diversification rates of flowering plants: energy versus climate change. Ecol. Lett. 11:173-83

Jansson R, Dynesius M. 2002. The fate of clades in a world of recurrent climatic change: Milankovitch oscillations and evolution. Annu. Rev. Ecol. Syst. 33:741-77

Jump AS, Hunt JM, Peñuelas J. 2006. Rapid climate change-related growth decline at the southern range edge of Fagus sylvatica. Glob. Change Biol. 12:2163-74

Jump AS, Peñuelas J. 2005. Running to stand still: adaptation and the response of plants to rapid climate change. Ecol. Lett. 8:1010-20

Kawecki TJ. 2008. Adaptation to marginal habitats. Annu. Rev. Ecol. Evol. Syst. 39:321-42

Knowles LL. 2009. Statistical phylogeography. Annu. Rev. Ecol. Evol. Syst. 40:593-612

Knox JS. 1997. A nine year demographic study of Helenium virginicum (Asteraceae), a narrow endemic seasonal wetland plant. Bull. Torrey Bot. Soc. 124:236-45

Le Quere C, Raupach MR, Canadell JG, Marland G, Bopp L, et al. 2009. Trends in the sources and sinks of carbon dioxide. Nat. Geosci. 2:831-36

Linares JC, Camarero JJ, Carreira JA. 2010a. Competition modulates the adaptation capacity of forests to climatic stress: insights from recent growth decline and death in relict stands of the Mediterranean fir Abies pinsapo. 7. Ecol. 98:592-603

Linares JC, Camarero JJ, Bowker MA, Ochoa V, Carreira JA. 2010b. Stand-structural effects on Heterobasidion abietinum-related mortality following drought events in Abies pinsapo. Oecologia 164:1107-19

Lozan A, Belokobylskij S, Van Achterberg C, Monaghan M. 2010. Diversity and distribution of Braconidae, a family of parasitoid wasps in the Central European peatbogs of South Bohemia, Czech Republic. F. Insect Sci. 10:16

Médail F, Diadema K. 2009. Glacial refugia influence plant diversity patterns in the Mediterranean Basin. 7. Biogeogr. 36:1333-45

Mejías JA, Arroyo J, Ojeda F. 2002. Reproductive ecology of Rhododendron ponticum (Ericaceae) in relict Mediterranean populations. Bot. F. Linn. Soc. 140:297-311
Highlights the distinctness and conservation value of pre-Last Glacial Maximum climate relicts.

Elegantly written review illustrating how climate variability nested across temporal scales can generate episodic dynamics of range expansion and contraction. 
Mendoza I, Zamora R, Castro J. 2009. A seeding experiment for testing tree-community recruitment under variable environments: implications for forest regeneration and conservation in Mediterranean habitats. Biol. Conserv. 142:1491-99

Merrill RM, Gutiérrez D, Lewis OT, Gutiérrez J, Díez SB, Wilson RJ. 2008. Combined effects of climate and biotic interactions on the elevational range of a phytophagous insect. F. Anim. Ecol. 77:145-55

Montesinos D, García-Fayos P, Verdú M. 2010. Relictual distribution reaches the top: elevation constrains fertility and leaf longevity in funiperus thurifera. Acta Oecol. 36:120-25

Moore BR, Donoghue MJ. 2007. Correlates of diversification in the plant clade Dipsacales: geographic movement and evolutionary innovations. Am. Nat. 170:S28-55

Morris WF, Pfister CA, Tuljapurkar S, Haridas CV, Boggs CL, et al. 2008. Longevity can buffer plant and animal populations against changing climatic variability. Ecology 89:19-25

Müller SW, Rusterholz HP, Baur B. 2006. Effects of forestry practices on relict plant species on limestone cliffs in the northern Swiss Jura mountains. For. Ecol. Manage. 237:227-36

Nekola JC. 1999. Paleorefugia and neorefugia: the influence of colonization history on community pattern and process. Ecology 90:2459-73

Niinemets U. 2010. Responses of forest trees to single and multiple environmental stresses from seedlings to mature plants: past stress history, stress interactions, tolerance and acclimation. Forest Ecol. Manag. 260:1623-39

Noack M. 1922. Über die seltenen nordischen Pflanzen in den Alpen. Eine florengeschichtliche Studie. Mitt. Bot. Mus. Univ. Zürich 95:1-288

Normand S, Treier UA, Randin C, Vittoz P, Antoine Guisan A, Svenning JC. 2009. Importance of abiotic stress as a range-limit determinant for European plants: insights from species responses to climatic gradients. Glob. Ecol. Biogeogr. 18:437-49

Ohlemüller R, Anderson BJ, Araújo MB, Butchart SHM, Kudrna O, et al. 2008. The coincidence of climatic and species rarity: high risk to small-range species from climate change. Biol. Lett. 4:568-72

Ohlemüller R, Huntley B, Normand S, Svenning JC. 2011. Potential source and sink locations for climate-driven species range shifts since the Last Glacial Maximum. Glob. Ecol. Biogeogr. In press; doi: 10.1111/j.1466-8238.2011.00674.x

Parmesan C. 2006. Ecological and evolutionary responses to recent climate change. Annu. Rev. Ecol. Evol. Syst. $37: 637-69$

Peñuelas J, Ogaya R, Boada M, Jump AS. 2007. Migration, invasion and decline: changes in recruitment and forest structure in a warming-linked shift of European beech forest in Catalonia (NE Spain). Ecography 30:829-37

Pepin L, Lundquist JD. 2008. Temperature trends at high elevations: patterns across the globe. Geophys. Res. Lett. 35:L14701; doi: 10.1029/2008G

Pereira HM, Leadley PW, Proença V, Alkemade R, Scharlemann JPW, et al. 2010. Scenarios for global biodiversity in the 21st century. Science 330:1496-501

Petit RJ, Hampe A. 2006. Some evolutionary consequences of being a tree. Annu. Rev. Ecol. Evol. Syst. 37:187214

Pfennig DW, Wund MA, Snell-Rood EC, Cruickshank T, Schlichting CD, Moczek AP. 2010. Phenotypic plasticity's impacts on diversification and speciation. Trends Ecol. Evol. 25:459-67

Popescu VD, Gibbs JA. 2009. Interactions between climate, beaver activity, and pond occupancy by the cold-adapted mink frog in New York State, USA. Biol. Conserv. 142:2059-68

Poorter H, Navas ML. 2003. Plant growth and competition at elevated $\mathrm{CO}_{2}$ : on winners, losers and functional groups. New Phytol. 157:175-98

Pound MJ, Haywood AM, Salzmann U, Riding JB, Lunt DJ, Hunter SJ. 2011. A Tortonian (Late Miocene, 11.61-7.25 Ma) global vegetation reconstruction. Palaeogeogr. Palaeoclimatol. Palaeoecol. 300:29-45

Pulido F, Valladares F, Calleja JA, Moreno G, González-Bornay G. 2008. Tertiary relict trees in a Mediterranean climate: abiotic constraints on the persistence of Prunus lusitanica at the eroding edge of its range. 7. Biogeogr. 35:1425-35

Qian H, Ricklefs RE. 2000. Large-scale processes and the Asian bias in species diversity of temperate plants. Nature 407:180-82 
Ramírez JM, Rey PJ, Alcantara JM, Sánchez-Lafuente AM. 2006. Altitude and woody cover control recruitment of Helleborus foetidus in a Mediterranean mountain area. Ecography 29:375-84

Reed TE, Schindler DE, Waples RS. 2011. Interacting effects of phenotypic plasticity and evolution on population persistence in a changing climate. Conserv. Biol. 25:56-63

Rodríguez-Sánchez F, Arroyo J. 2008. Reconstructing the demise of Tethyan plants: climate-driven range dynamics of Laurus since the Pliocene. Glob. Ecol. Biogeogr. 17:685-95

Rodríguez-Sánchez F, Pérez-Barrales R, Ojeda F, Vargas P, Arroyo J. 2008. The Strait of Gibraltar as a melting pot for plant biodiversity. Quat. Sci. Rev. 27:2100-17

Rull V. 2009. Microrefugia. 7. Biogeogr. 36:481-84

Sanz R, Pulido F, Camarero J. 2011. Boreal trees in the Mediterranean: recruitment of downy birch (Betula $a l b a)$ at its southern range limit. Ann. Forest Sci. 68:793-802

Sanz R, Pulido F, Nogués-Bravo D. 2009. Predicting mechanisms across scales: amplified effects of abiotic constraints in the recruitment of yew Taxus baccata. Ecography 32:1-8

Sarris D, Christodoulakis D, Körner C. 2007. Recent decline in precipitation and tree growth in the eastern Mediterranean. Glob. Change Biol. 13:1187-200

Scherrer D, Körner C. 2010. Infra-red thermometry of alpine landscapes challenges climatic warming projections. Glob. Change Biol. 16:2602-13

Schneeweiss GM, Schönswetter P. 2010. The wide but disjunct range of the European mountain plant $A n-$ drosace lactea L. (Primulaceae) reflects Late Pleistocene range fragmentation and post-glacial distributional stasis. 7. Biogeogr. 37:2016-25

Spitzer K, Danks HV. 2006. Insect biodiversity of boreal peat bogs. Annu. Rev. Entomol. 51:137-61

Sthultz CM, Gehring CA, Witham TG. 2009. Deadly combination of genes and drought: increased mortality of herbivore-resistant trees in a foundation species. Glob. Change Biol. 15:1949-61

Suggitt AJ, Gillingham PK, Hill JK, Huntley B, Kunin WE, et al. 2011. Habitat microclimates drive fine-scale variation in extreme temperatures. Oikos 120:1-8

Thomas JA, Rose RJ, Thomas CD, Webb NR. 1999. Intraspecific variation in habitat availability among ectothermic animals near their climatic limits and their centres of range. Funct. Ecol. 13(Suppl. 1):55-64

Thuiller W, Albert C, Araújo MB, Berry PM, Cabeza M et al. 2008. Predicting global change impacts on plant species' distributions: future challenges. Perspect. Plant Ecol. Evol. Syst. 9:137-52

Turlure C, Choutt J, Baguette M, van Dyck H. 2010. Microclimatic buffering and resource-based habitat in a glacial relict butterfly: significance for conservation under climate change. Glob. Change Biol. 16:1883-93

Turlure C, Van Dyck H, Schtickzelle N, Baguette M. 2009. Resource-based definition of the habitat, niche overlap and conservation of two glacial relict butterflies. Oikos 118:950-60

Ursenbacher S, Alvarez C, Armbruster GFJ, Baur B. 2010. High population differentiation in the rock-dwelling land snail (Trochulus caelatus) endemic to the Swiss Jura Mountains. Conserv. Genet. 11:1265-71

Valiente-Banuet A, Vital Rumebe A, Verdú M, Callaway RM. 2006. Modern Quaternary plant lineages promote diversity through facilitation of ancient Tertiary lineages. Proc. Natl. Acad. Sci. USA 103:16812 17

van Mantgem PJ, Stephenson NL. 2007. Apparent climatically induced increase of tree mortality rates in a temperate forest. Ecol. Lett. 10:909-16

Vanwalleghem T, Meentemeyer RK. 2009. Predicting forest microclimate in heterogeneous landscapes. Ecosystems 12:1158-72

Waite TA, Strickland D. 2006. Climate change and the demographic demise of a hoarding bird living on the edge. Proc. R. Soc. London Ser. B 273:2809-13

Wanner H, Beer J, Bütikofer J, Crowley TJ, Cubasch U, et al. 2008. Mid- to Late Holocene climate change: an overview. Quat. Sci. Rev. 27:1791-828

Willis KJ, Baghwat SA. 2009. Biodiversity and climate change. Science 326:806-7
Explores the relationships between selection, phenotypic plasticity, and demography in the context of climate change.

Discusses how to implement processes occurring at the retreating limit of species ranges into species distribution models. 